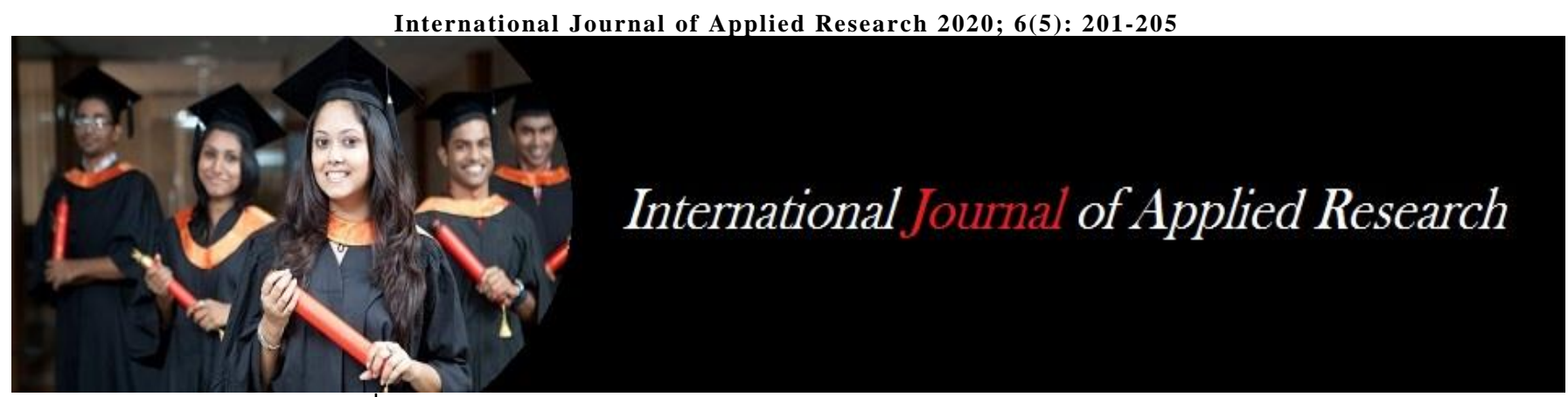

ISSN Print: 2394-7500 ISSN Online: 2394-5869 Impact Factor: 5.2 IJAR 2020; 6(5): 102-105 www.allresearchjournal.com

Received: 01-03-2020 Accepted: 02-04-2020

Salikhov Nodir Jamolovich Base Doctoral Student of Bukhara State University, Uzbekistan

\section{Zivavitdinova Nafisa}

Mukhammedovna, Bukhara Engineering and Technology Institute, Docent of the Department "Management", Uzbekistan.
Correspondence Author: Salikhov Nodir Jamolovich Base Doctoral Student of Bukhara State University, Uzbekistan

\section{Management of innovative activities of preschool education organizations in the educational process}

\section{Salikhov Nodir Jamolovich and Ziyavitdinova Nafisa Mukhammedovna}

\begin{abstract}
Annotation: This article deals with the management of innovative activities of organizations of preschool education. Creation of the necessary conditions for the implementation of the goals and objectives aimed at introducing innovative procedures into the educational process of a preschool institution.
\end{abstract}

Keywords: Education, management, innovation, innovation process, innovation criteria, perspectives, learning technology

\section{Introduction}

Education is a focused process of education and training, taking into account the interests of human, society and the state. Throughout the history of the development of pedagogical science, the category of education was considered from various perspectives: as a process, as a result, as a system and as a value. At the present stage of social development, education should be studied from a slightly different angle, namely, as an important component of a person's cultural values, as accumulated human capital and social welfare.

At present, the sphere of education is becoming a priority, and the content of education is one of the factors of the economic and social progress of society, which undoubtedly indicates that education should be focused on ensuring self-determination of the personality, creating conditions for its self-realization both in the personal and professionally. Education is aimed at ensuring an adequate level of general and professional culture of each individual person, mental development of a person, his professional qualifications and competence, adequate to the world community.

Today's world is, first of all, the humanization and democratization of interhuman relations. These are new forms of communication, new forms of contacts between people and the development of a tolerant attitude towards other peoples. The pedagogical problem is fraught with the universal in the sense that it has a universal character and is of common value for all the peoples of the world.

Education as a sphere of spreading fundamental and applied scientific knowledge about nature, society, culture has the following reproduction cycle: knowledge and culture of past eras-real living knowledge-the embodiment of knowledge and culture in reality and their rooting in real life. Over time, the present and future, together with the knowledge contained in them, in their carriers turns into the past, which must be mastered by descendants.

A society in constant development imposes new requirements on a person, poses new challenges for him, and through education often finds the right solutions to problems related to trends and contradictions of the 21 st century. Among the most basic requirements of modern society to a person are:

Learning ability, i.e. human ability to constantly increase the level of knowledge, the development of new activities, including professional.

- Intellectual and physical development, ensuring success in the development of new technologies and maintaining health.

- Creativity, i.e. the ability to think and act creatively not only in the educational process, but also in future professional activities.

- $\quad$ Spirituality, patriotism, humanity and tolerance. 
The state of modern education is characterized by a change in pedagogical paradigms. Emerging in modern education, new systems, technologies, approaches give rise to a new psychological and pedagogical attitude to the learning process, which was called innovative. The word "innovation" comes from Latin and in translation means "update, new, change." Innovation processes - innovation, the introduction of new content and new methods that have other properties associated with the change of semantic guidelines.

A distinctive feature of a modern preschool educational institution is the introduction of innovations in the pedagogical process, the growth of the variety of educational Educational technologies used in pedagogical activity.

At the present stage, innovative ideas in education can solve the problems of quality in preschool education. The practice of many teachers on the basis of innovative pedagogical approaches has shown the success of this process.

The professional activity of teachers of a preschool educational organization is multifaceted and requires certain knowledge, skills, and qualities, as well as the possession of professionally significant attitudes and personal qualities, theoretical knowledge, and professional skills.

Innovation often refers to changes within the system. In the pedagogical interpretation and in the most general sense, innovations mean innovations that contribute to improving the development of the educational process and achieving high results in this area. However, it is worth noting that innovations can sometimes also cause a reverse set of circumstances and lead to a deterioration of the system.

It is very important to understand that the essence is by no means in the innovations themselves, but precisely in what result they show. Many scientists argue that, having borrowed the term, we were not able to understand its true meaning. To indicate innovations, i.e. replacing something with something else, more advanced, new, there is a normative English word "novation". Innovation means an innovation that is implemented in the system due to its own (in - inside) resources (reserves). Due to the ambiguity of the concept of "new" (especially in the field of education), new publications constantly appear in the pedagogical literature concerning this issue. So, for example, in the article of M. S. Burgin "Innovation and novelty in pedagogy" the author distinguishes different levels of novelty in pedagogy.

I.P. Podlasov gives such a definition to the word innovation: "These are necessarily progressive innovations that advance practice forward, and innovations arise, as a rule, on a scientific basis." Any method of educator in working with children can be mistakenly interpreted as a method, and even worse - as an innovation. Learning technology is a combination of forms, methods, techniques and means of transmitting social and professional experience in the learning process. Unfortunately, often not only practitioners, but also scientists allow themselves the free use of the terms "methodology" and "learning technology".

So, pedagogical technology covers the scientifically-based project of the pedagogical process (or in another way - the model of the pedagogical system) and the system of actions of the educator and pupils who act in accordance with this project. It is precisely this concept of pedagogical technology that has been reinforced recently in preschool pedagogy. It went through a certain evolution. Initially, this concept was understood as the use of various technical means in education, that is, the use of engineering and similar technologies in education.

A harmonious educational process in a modern preschool educational organization is possible only if it is considered as a complete reproduction of a previously designed pedagogical technology, i.e. clearly defined tasks in conjunction with adequate technology to solve them. This makes it possible to turn the activities of a preschool educational organization with a poorly ordered set of actions by teachers into a focused process of the entire teaching staff.

According to I.P. Podlasov, it should be called a misunderstanding that today every second teacher works (or at least declares it) in a search and research mode, shaking the already hectic boat of educational technologies, increasing the already great uncertainty of the results of the educational process. One can endlessly be proud of the asceticism of teachers, emphasize their civic courage and devotion to the profession, admire the variety of authoring systems and techniques, and at the same time not take a step towards advancement in improving the technology of the educational process.

Despite the apparent diversity of technological systems, educational institutions have slipped into the swamp of primitive pedagogical supervision. It is worth noting that today the vast majority of teachers do not know the classical technological procedures, trying to prove that they are making efforts to introduce innovations in pedagogical activity, hiding their lack of professionalism behind the slogans of "creativity" and "author's methods". As a result, no one at this rate of development can guarantee the quality of training and education.

Any activity can be art or technology. Art is based on intuition, technology is based on the laws of science. Everything begins with art, with technology - it ends, and so cyclically repeats, one replaces the other.

Innovative activity in pedagogy is a separate method of cognition, with the help of which, in natural or artificially created conditions that are monitored and controlled, the educational phenomenon is investigated, a new way to solve a pedagogical problem or its predicted problem.

Today, much of past experience does not meet the requirements of a modern preschool educational organization, as well as of society as a whole. Therefore, in order for the educational industry to effectively develop, new ideas, new technologies for training and education, and proper management of the institution are needed. All this requires testing in innovation, which should either prove the feasibility and effectiveness of the implementation of the put forward idea, or refute it. However, innovation is not a fashion; it cannot be put into practice without proper scientific justification.

\section{Methods}

A well-organized innovation should constantly be in a state of scientific research and be capable of prognostic assessment of the situation in order to timely recognize the problem, lag, or, conversely, the progressive course of events, so that it is possible to improve existing innovative technologies or at least maintain a state of a certain level. For this purpose, it is necessary to process a lot of scientific and methodological literature on problems to be solved.

Thanks to the implementation of innovative ideas, it is possible to systematize and classify scientific information, conduct a thorough analysis, where the most progressive 
ideas will be singled out, which should be generalized, compared with mass and promising pedagogical experience, existing concepts or relevant directions for improving the educational process. The focus of innovation is determined by:

- The objective needs of society in updating the work of the institution;

- A social order identified by education authorities as a result of a scientific forecast;

- Real conditions and opportunities in a given period of its development; interests of managers, teachers - those who will organize and conduct innovative activities.

- Innovative activities in the preschool educational organization are carried out in the following main areas:

- Development of new educational content;

- The introduction of new systems, methods, technologies, techniques, teaching aids and parenting;

- Creation of preschool institutions with priority areas of development;

- Application of optimal management mechanisms for educational institutions.

Thus, the essence of the innovative activity of preschool educational institutions is to carry out managerial activities aimed at profound internal changes in the structure of the system using the latest methodological developments and technologies. This includes a change in the algorithm for conducting internal education quality control; creating a unified management program; development of a concept for the development of preschool educational organizations, the transition to a new management mechanism of particular importance in the innovative activities of preschool educational organizations is the following:

Methodological Work: individualization of forms and methods of methodological work, depending on the level of professional skill of teachers; creation of a system of continuing education of teachers; the development of individual programs for the creative development of a teacher and the like.

In the content of education: the introduction of new programs; development of individual educational programs for children; additional educational services, etc.

In the methods of working with children: the simplest experimentation and experiments; modeling situations; independent search by children for solutions to problems and more. In a developing environment: creating a room for psychological relief; children's theater studios, circles. It is noticeable that innovative processes are able to penetrate various spheres of activity of preschool educational institutions. Thus, the introduction of innovative processes in the activities of preschool educational organizations is the most important condition for improving and reforming the system of preschool education.

Along with all aspects, it is important to note that innovation is a process that develops at certain stages and allows the institution to move to a higher level of development in the creation, development, development, development, use and dissemination of innovations (new methods, technologies, programs). The general goal of innovative activity in a preschool institution is to increase the efficiency of the learning process and to obtain better results. In this situation, professional competence is especially important, which is based on the personal and professional development of teachers and managers. for this reason, at present, the sphere of innovation activity includes not just individual preschool institutions and innovative teachers, but almost every preschool institution; teachers of preschool educational institutions are involved in innovative processes related to updating the content of preschool education. Any innovation process is probabilistic in nature, and not all of its consequences can be predicted. The timely detection and correction of many errors and omissions even at the project or model level will help drawing up an analytical justification and an innovative program or model of innovative work of a preschool educational institution.

The goals and objectives of innovation are based on a thorough analysis of the current situation in a preschool educational institution on the one hand, and from forecasts of its development on the other. The selected goals and objectives of innovation should be coordinated and approved by the majority of the teaching staff, they should also be realistic, adapted to new conditions, should increase the level of motivation and stimulation, provide control. When managing innovative processes in a modern preschool educational institution (taking into account the forecast of final results), the bulk of these actions are discussed collectively. The largest innovation activities should be developed as a group method.

The management of innovative activity in a preschool institution is carried out according to progressive trends in the innovative educational process, taking into account the objective capabilities of teachers, their level of professional and methodological competence, willingness to master, introduce and develop innovations that are in demand by modern educational practice.

An analysis of the problems of innovation in pedagogical activity inevitably raises the task of assessing and developing the theoretical foundations for the formation of innovative activity by department heads and senior educators. This task has a deep socio-pedagogical meaning, since the success of transformations in the education system and the prospects for the development of a preschool institution depend on its solution.

One of the trends in the development of innovative technologies is also the inclusion in the educational process of not only cognitive, but also the emotional and personal sphere of man.

The preparation of managers, senior educators for innovative activity is effective if it unfolds in appropriate educational forms and solves two interrelated tasks: the formation of innovative readiness for the perception of innovation and training in the ability to act in a new way. Therefore, the goal of managing innovative processes in a preschool educational institution, which is assigned to the head and methodologist, is to ensure the implementation of innovative strategies, the functioning of innovative structural units and the entire teaching staff to achieve high education efficiency and improve its quality.

The main activities of the head of the preschool educational organization in the Republic of Uzbekistan:

- Carries out general management in accordance with the Charter and legislation of the Republic of Uzbekistan.

- Provides system administrative-economic and educational work of the institution.

- Defines the goals and objectives of the development of the institution, strategy, decisions on the program planning of work. 
- Determines the management structure of the preschool educational institution, staffing;

- Carries out hiring, selection and placement of teaching staff.

- Determines the duties of employees, creates the conditions for their professional skills.

- Supervises the work of a senior educator, farm manager, specialists and maintenance personnel.

- Provides overall guidance to the teaching staff of the organization.

- Organizes the control of the quality of knowledge, skills of students, their level of education and development.

- Organizes work to strengthen the educational - material base, ensuring its safety and effective use.

- Participates in the work of self-government bodies, assists in the work of public organizations; controls the management of paperwork and documentation, communicates with various social partners.

In the process of transition of the educational institution to the development mode, i.e. the introduction of the innovation process distinguished the following stages:

1. Relevance, awareness of the need for future innovations, the presence of a kind of "ideological inspirer" of future innovations.

2. Prediction the development over the long term of changes in the educational process and the state of the control object.

3. Planning - the process of developing an action plan and many different interrelated decisions regarding the innovative activities of the organization to achieve its innovative goals, as well as the most effective means of implementing this plan in specific conditions.

4. Team building. An important team of ideological supporters of innovation from among the teaching staff.

5. Problem analysis determination of the main problem of teachers today in the introduction of innovation.

6. Definition of specific management actions to implement the developed idea, ie drawing up a plan or implementation program.

7. The organizational function in innovation management is the establishment of permanent and temporary relationships between all departments and individual performers.

8. Tracking the first steps to implement innovation in order to correct subsequent management actions.

9. Regulation monitoring the implementation of innovations, and in the event of deviations, the organization of measures for their immediate elimination.

10. Coordination ensuring coherence in the work of all links of the innovation field, as well as maintaining, maintaining and improving the established links between them.

11. Motivation encouraging teachers to innovate, their interest in the results of their work.

12. Control checking the organization of the innovation process, the plan for creating and implementing innovations.

The priority tasks of innovative activity and ensuring the quality of innovative and experimental activity are:

- Attracting an experienced scientific adviser to the innovation process, able to lead the work in this direction and train the teaching staff in accordance with the scientific approaches of innovation.
- The formation of an innovative environment in kindergarten through the creation of a system of information and methodological support and the practical implementation of innovations in the educational process;

- Creation of conditions for the mastery of teachers of a specific innovative technology. For example, mastery of interactive technologies and the mechanism of their implementation in the educational process;

- Creating conditions for introducing innovations into the system of work of each teacher.

When managing innovative activities, the head takes into account the most frequently encountered difficulties in the work of the teachers of his educational institution and in the construction of a holistic pedagogical innovative process.

A joint discussion of the concept, the choice of innovations, an attempt to solve problems stimulates the innovation activity of the whole team.

An important role belongs to the creative self-realization of teachers, since creativity is a necessary personal quality that allows a person to be realized in rapidly changing conditions and navigate in an ever-expanding information field. Correctly organized innovative activity can, in our opinion, expand the possibilities for the creative realization of teachers and, thus, prevent emotional burnout.

We would like to emphasize that such a modeling of professional positions and professional relationships is possible only when mutual understanding, mutual interest, a certain level of professional competence of the supervisor, the head of the institution and teachers are achieved.

\section{Conclusion}

Thus, management in the system of a preschool educational organization is a carefully designed process of interaction between the manager and his employees, aimed at achieving a qualitative result, where the main thing is to improve the quality of the educational process. As a result, the reform of preschool education in order to more fully satisfy the needs of parents and the interests of children presents new requirements for preschool educational institutions, which contributes to further improvement of the educational process in preschool institutions. At such a pace of development, where one serves as an incentive for the development of the other, it is quite possible to achieve qualitative results in the application of innovations.

\section{References}

1. Declar from the President of the Republic of Uzbekistan Sh. Mirziyoyev, the upper house, 12/28/2018.

2. Aleksanina NS. Management of innovative activity of educational institutions in the school district // Abstract of the dissertation of the candidate of pedagogical sciences M, 2007, 23.

3. Belaya K. Self-education of teachers of a preschool institution/Ksenia Belaya//Educator-methodologist of a preschool institution. 2010; 2:17-19.

4. Beh ID. Parenting: In 2kn / I.D Beh K: Lybid, 2003-Prince 1: Person-oriented approach: theoretical and technological foundations of sciences, edition K: Lybid, 2013, 21-25.

5. Burgin M.S. Innovation and novelty in pedagogy / M.S. Burgin // Soviet pedagogy. 2015; 12:33-40. 
6. Burkova LV. Pedagogical innovations and their diagnostics: theoretical aspect-K: Science World, 2014, $37-45$.

7. Vasilenko OV. Innovation management: A training manual/OV Vasilenko, V.G Shmatko, Ed V.O. Vasilenko M TSUL, Phoenix, 2013, 9-11.

8. Vedernikova LV, Povoroznyuk OA. The interaction of a comprehensive school and a pedagogical university in a sociocultural context // Higher Education in Russia, No eleven, 2013.

9. Dichkivskaya I. Socio-pedagogical competence: innovative approaches / I. Dichkivskaya // Preschool education, 2010; 1:7-11.

10. Dolgova VI, Tkachenko VA. Management of innovative processes in education: Essence, patterns and trends // Science and business: Development paths 2012. 2014; 7(13):17-22.

11. Dolinnaya A. Methodical work in the system of preschool education / A. Dolinnaya, A. Burovaya // Preschool education, 2008; 8:6-10.

12. Preschool education. Normative legal regulation/Comp L Gurash, T Voronina M. Publishing. School World House: Publ. Galitsyna, 2016, 120.

13. Ilyenko LP. New models of methodological services in educational institutions [Text] / L.P Ilyenko M: Publishing Arcti, 1999; 48:8-23.

14. Kirilina MV. Improving the socio-pedagogical competence of teachers of preschool educational institutions in the process of innovative educational activities // Bulletin of the Perm State Humanitarian and Pedagogical University, Psychological and pedagogical sciences. 2013; 1:2.

15. Book of the head of a preschool educational institution: Reference and methodical publication / Comp O.A. Kopeikina: L.V Gurash. -Kharkiv: Torsing plus, 2016, 512.

16. Kondrashova NV. Actual problems and development trends of preschool education in Russia at the present stage // Prospects of science. 2014; 11:24-31.

17. Krutoy KL. Innovative activity in a preschool educational institution: methodological aspect / K.L Krutoy NV Makovetskaya-Zaporozhye: LIPS, 2014; 19:64-70.

18. Krutoy KL. Innovative activity in a modern preschool educational institution: methodological aspect / K.L Krutoy, N.V Makovetska-Zaporozhye: LLC "LIPS" LTD, 2012, 15-39.

19. Krutoy KP. Massive forms of methodological work with teachers in a modern preschool educational institution / Zag ed. K.P Krutoy-Zaporozhye: LIPS, $2014,87$.

20. Krushelnitskaya AV. Methodology and organization of scientific research: textbook benefits/A.V Krushelnitskaya K: Kondor, 2013, 192.

21. Kuznetsova ES, Semenets NV. Use of information technology in the activities of a preschool educational institution as a reflection of the informational and communicative competence of the head // Modern preschool education theory and practice. 2013; 8:40.

22. Kuznetsova E, Volobueva L. Introduction of innovations in managerial activity of the head of a preschool educational institution Litres, 2017.

23. Kuchergina OV. Formation of an innovative culture of teachers of a preschool educational institution // Yaroslavl Pedagogical Bulletin. 20131 T.2:1.
24. Podlasy I, Podlasy A. Pedagogical innovations // Native School. 1998; 2:3-4.

25. Yakovleva GV. Management of innovative activity in a modern preschool educational institution // Theory and Practice of Education Management, 2015, 4. 